\title{
Vorwort
}

\section{Endlich -}

Es war im Sommer 1893. Ich war Rechtspraktikant am Bezirksamt Miesbach, einer Verwaltungsbehörde an der Landesgrenze, und las in freien Stunden Bars Theorie und Praxis des internationalen Privatrechts. Damals ist mir der Gedanke gekommen, es müsse gleichartige Fragen wie im internationalen Privatrecht auch für das Verwaltungsrecht geben, wurden die ersten Notizen über den Gegenstand zu Papier gebracht. Als ich einige Jahre später, um mir Klärung über sie zu verschaffen, die leitenden Gedanken für ein internationales Privatrecht niederschrieb, wurden die Aufzeichnungen auf das Prozeßrecht, Strafrecht und Verwaltungsrecht erstreckt, und es hat sich zu jener Zeit das wissenschaftliche Bild geformt, wie es mir seither vor Augen steht. Wenig später, bei meiner Habilitation als Privatdozent, 1901, hatte ich Thesen aufzustellen, die ich verteidigen sollte. Unter ihnen befand sich der Satz: „Das internationale Verwaltungsrecht ist ein neu zu begründender Zweig des internationalen Privatrechts" - es ist freilich niemand aufgetreten, der die These diskutiert hätte. Und dann sind nach einander die Bände dieses Werkes erschienen. Sie haben, auf einen ungeschriebenen Allgemeinen Teil ausgerichtet, zuerst die einzelnen Verwaltungseinrichtungen behandelt - und das konnte bei der Unbekanntheit des Gegenstands nicht anders sein, sollte jener Allgemeine Teil nicht Gefahr laufen, sich in blutlosen Abstraktionen zu erschöpfen oder gar voreiligen Verallgemeinerungen zum Opfer zu fallen: Es war freilich ein Wagnis, so zu verfahren, und es ist glimpflich genug ausgegangen: die Leitgedanken eines solchen Allgemeinen Teils haben dem Kreuzverhör der vielen Verwaltungs- 
einrichtungen, für die sie gelten sollten, und der nunmehrigen zusammenfassenden Nachprüfung nahezu ausnahmslos standgehalten. Ich darf das gleiche für die meisten unter den Fragen zweiten Ranges feststellen. Bei den Verzweigungen der allgemeinen Lehren ins Einzelne hat sich eine Revision früher geäußerter Meinungen nicht ganz selten erforderlich gezeigt. Es ist auf solche Abweichungen jeweils hingewiesen worden.

Das Werk hatte sich zunächst die bescheidenere Aufgabe gestellt, an Hand praktisch gewordener Fragen die Problemstellung zu beleuchten, die Verfasser an den Gegenstand heranbrachte. Dafür konnte geltendes und früheres Recht, heimische und fremde Regelung dienen. Den Stoff $z u$ beschaffen, wurden die internationalrechtlichen Zeitschriften durchgearbeitet, um nichts Wesentliches zu übersehen, ein materielles Verwaltungsrecht beigezogen (als dem Verfasser am nächsten vertraut, das bayerische Verwaltungsrecht mit seinen Ergänzungen durch Reichsrecht), sonst noch Zufallsergebnisse, welche Lektüre verschiedenster Art abwarf. Vom zweiten Band an hat sich das Werk weitere Ziele gesteckt. Die Erfahrungen, die Verfasser bei der Bearbeitung des ersten Bandes sammeln konnte, und die seither erfolgte Besserung der Bibliotheksverhältnisse ließen es nicht mehr völlig aussichtslos erscheinen, über den Rahmen von Beispielen binaus die Verwaltungseinrichtungen der wichtigeren Staaten systematisch auf ihre Stellung im internationalen Verwaltungsrecht zu prüfen wenngleich die Unmöglichkeit, zu den ersten Quellen durchzudringen, bei der Lückenhaftigkeit der Hilfsmittel diesem Bestreben überaus häufig Einhalt gebot.

Auch der Allgemeine Teil des Werkes ist zunächst auf die innere Verwaltung gerichtet. Sollte er indessen wirklich die ihm zugeschriebene Allgemeinheit besitzen, so war es unausweichlich, auch auf die andern Teile der Verwaltung auszugreifen, und wenn die Annahme des Verfassers zutrifft, da $B$ die hier entwickelten Lehren für alle Zweige des internationalen öffentlichen Rechts entsprechend giltig sind, für das internationale Zivilrecht zum größeren Teile Übereinstimmung, zum Teil aber auch Verschiedenheit ihnen gegenüber besteht, so waren auch Ausgriffe auf diese Bereiche nicht völlig zu 
entbehren. So ist dieser Allgemeine Teil unerwünscht angeschwollen. Und der Wunsch, saubere Gedankenarbeit zu tun, hat seinen Umfang noch einmal gesteigert.

Nun ist mit dem vorliegenden Band ein umfängliches Werk zum Abschluß gekommen, und es mag zweckmäBig sein, einem Leser, dem die Arbeit noch in allen ihren Teilen fremd ist, schon an dieser Stelle einen knappen Hinweis zu geben,

was das Werk will:

Zunächst aber sei gesagt, was dies Werk nicht will. Es hat gar nichts zu tun mit einem sogenannten internationalen Verwaltungsrecht, das von dem Recht gemeinsamer Verwaltung innerhalb einer Staatengruppe oder auch innerhalb der gesamten rölkerrechtlichen $\mathrm{Ge}-$ meinschaft zu handeln vorgibt. Die Arbeit bezieht sich auf das Verwaltungsrecht der einzelnen Staaten. Auch auf diesem Boden soll sie nicht rechtsvergleichendes Material zusammentragen, will auch nicht sammeln, was sich innerhalb des Verwaltungsrechts irgendwie auf Ausland und Ausländer bezieht. Sie strebt vielmehr einem scharfumrissenen Ziel zu: für das Verwaltungsrecht, und zunächst für das Recht der inneren Verwaltung diejenigen Lehren zu entwickeln, die für das Privatrecht, dessen Sonderart entsprechend, die Lehre vom internationalen Privatrecht längst behandelt hat. Also und in erster Reihe, die örtlichen Grenzen aufzuzeigen, innerhalb deren das Verwaltungsrecht eines Staats für dessen verschiedene Aufgaben Geltung besitzt, und die rechtliche Überwirkung festzustellen, die von fremder Verwaltung auf das Recht dieses Staates ausgeübt wird.

Mün chen, den 1. April 1936. 